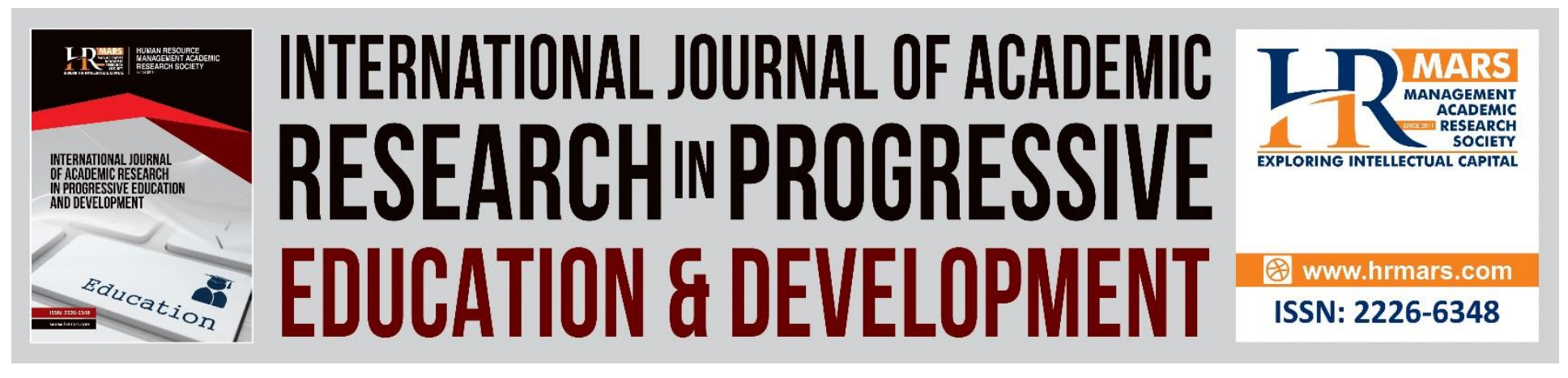

\title{
Workplace Learning Research Trends in 21 Century: A Bibliometric Review of 20 Years' Research
}

\section{Rouhollah Khodabandelou, Faeza ALThamari and Zahra Pourjafarian}

To Link this Article: http://dx.doi.org/10.6007/IJARPED/v10-i2/10251

DOI:10.6007/IJARPED/v10-i2/10251

Received: 18 March 2021, Revised: 23 April 2021, Accepted: 11 May 2021

Published Online: 25 May 2021

In-Text Citation: (Khodabandelou et al., 2021)

To Cite this Article: Khodabandelou, R., ALThamari, F., \& Pourjafarian, Z. (2021). Workplace Learning Research Trends in 21 Century: A Bibliometric Review of 20 Years' Research. International Journal of Academic Research in Progressive Education and Development, 10(2), 782-796.

Copyright: (C) 2021 The Author(s)

Published by Human Resource Management Academic Research Society (www.hrmars.com)

This article is published under the Creative Commons Attribution (CC BY 4.0) license. Anyone may reproduce, distribute, translate and create derivative works of this article (for both commercial and non-commercial purposes), subject to full attribution to the original publication and authors. The full terms of this license may be seen

at: http://creativecommons.org/licences/by/4.0/legalcode

Vol. 10(2) 2021, Pg. 782 - 796

http://hrmars.com/index.php/pages/detail/IJARPED

JOURNAL HOMEPAGE

Full Terms \& Conditions of access and use can be found at http://hrmars.com/index.php/pages/detail/publication-ethics 


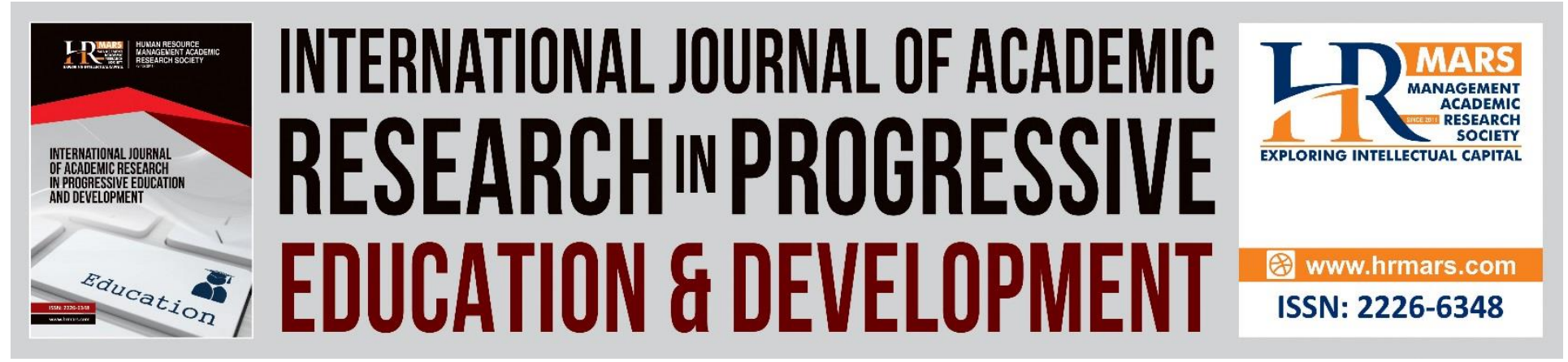

\title{
Workplace Learning Research Trends in 21 Century: A Bibliometric Review of 20 Years' Research
}

\author{
Rouhollah Khodabandelou1, Faeza ALThamari² and Zahra \\ Pourjafarian ${ }^{3}$
}

${ }^{1}$ Instructional and learning technology, College of Education, Sultan Qaboos University, Muscat, 123, Oman, ${ }^{2}$ Art Education, College of Education, Sultan Qaboos University, Muscat, 123, Oman, ${ }^{3}$ Education and Counselling, Faculty of Literature, Humanities and Social Science, Science and Research Branch Islamic Azad University, Tehran, Iran

\begin{abstract}
Workplace Learning (WL) is one of the most attractive areas of development in education, and it is main concerns at the universities. Workplace Learning and its new focus of learning is on changing business perspectives, and educational institutions are working to become more involved with the world of work than ever before. The growth of research on WL has resulted in interesting challenges for institutions. A considerable amount of literature has been published on WL in order to increase knowledge in this field of study. Some of these contributions are in literature review format. The present study extends the review of the literature by providing a general perspective and going beyond WL. It uses a combination of bibliometric technique and thematic analysis to comprehensively examine and review the $W L$ field. For the purpose of this study, 1,121 existing documents from 2000 to 2020 which have been indexed in Web of Science database are investigated. Additionally, the researchers analyzed a sample of 10 most cited articles to identify the quality and impact. Major research trends in WL research literature which has been investigated including variations across publication years, identifying active research areas, and the most prolific authors, organizations and counties, co-authorship. It can be said that the current study is describing the current state of workplace learning. With the intent of informing future research and practice in the emerging discipline of workplace learning
\end{abstract}

Keywords: Learning, Workplace Learning, Science Mapping, Education.

\section{Introduction}

Highlight On 22 August 2019, a SCOPUS basic search using titles, abstracts and keywords for the phrase of which the oldest was dated 1988. In spite of these relatively few and recent publications, the concept of workplace learning-defined, in this study, as learning that occurs at workplace (Hord, 1997) - is believed to have a much ancient history. In fact, there existed some form of arrangements even in the ancient Greek whereby apprentice training was conducted 
within workers' cooperation (Wenger and Snyder, 2000). These rather informal provisions of learning in the workplace were regarded as the hallmark of communities of practice (one of the few ways in which workplace learning is described in the literature) although the exact term was coined much later in the 1990s (Wenger, 1998).

\section{Literature Review}

Learning Communities Concepts

Apart from the notion of communities of practice, a concept closely related to workplace learning known as the learning communities grew side-by-side. The foundation of learning communities has its roots linked to theories of educational enquiry as anticipated by Dewey (1929). According to Dewey, educational practices provide data which forms the basis for problems of enquiry. The earliest attempts to use strategies of enquiry in education such as collaborative problem-solving can be dated back to the beginning of the 1900s (Murphy and WL 32,4 Adams, 1998). These collaborative problem-solving groups have gradually turned into learning communities during 1900-1950 (Stoll et al., 2006). The concept of learning communities gradually developed, and in the second half of the twentieth century, it gave way into professional learning communities (PLCS) - a term coined by (Hord, 1997). Thus, the notion of workplace learning essentially incorporates the concepts embedded in communities of practice, learning communities and, PLCs. Owing to the long history of these concepts, it is anticipated that there would be a huge amount of literary and scholarly work related to these topics. As such, there is a need to conduct a bibliometric analysis of these topics to find out the development of knowledge in this area. Bibliometric studies have been conducted in various fields; for instance, in medicine (Bayram et al., 2016; Kolkailah et al., 2018; Liu et al., 2019), business (Fellnhofer, 2019), management (Zupic and Cater, 2015), environment (Zhang et al., 2019) and education (Hallinger, 2019; Hallinger and Kovacevic, 2019). Nonetheless, to find out if there exist any bibliometric studies conducted on the topic of workplace learning, during August 2019, an advanced search using the same parameters (and the term "bibliometric") as our main data search was conducted in SCOPUS database.

Learning Communities from Bibliometric Perspective

The query generated only six results, in total, of which two of the publications are somewhat related to the present enquiry. The first one is the bibliometric analysis by Hallinger and Kulophas (2019) which is limited to only teacher professional learning whereas we intend to conduct a much broader search to include learning in workplace in all fields. The second study by Hernández et al. (2017) is limited to learning communities that are based on information and communication technology (ICT) while our enquiry included both ICT and non-ICT based learning in the workplace. The rest of the publications are significantly different from our conceptualisation of the problem. In sum, based on the search results in SCOPUS, there are no bibliometric studies conducted to date that summarises the scholarly efforts on workplace learning in its entirety. Hence, we conducted the present bibliometric analysis to fill the identified void in the literature, and with the following purposes:

- To explore the pattern of publications and citations of the 100 most-cited articles on workplace learning; 
- To examine the contribution and collaboration of various countries to the publication of the 100 most-cited articles on workplace learning;

- To identify the top journals that have published the 100 most-cited articles on workplace learning and analyse the characteristics of these journals;

- To identify the key concepts that are explored in the 100 most-cited articles on workplace learning; and

- To provide insights into the trend in the citation (coupling networks) of the 100 mostcited articles on workplace learning.

\section{Method}

This paper engages science mapping to produce an overview of the existing knowledge base on the topic of workplace learning. Science mapping is a method for conducting a bibliometric analysis of literature and scholarly work (Morris and Van DerVeer Martens, 2008). It is an appealing sub-class of bibliometric (or scientometric) analysis in which researchers attempt to explore and graphically display the connections among the various concepts (scientific knowledge) as it evolve and grow over the years (Small, 1997; Van Eck And Waltman, 2014). These connections can be analysed using various units such as keyword, author, publication, journal, institution and country as the basis for enquiry (Cobo et al., 2012).

According to Cobo et al (2012), the procedure in a science mapping analysis can be generally described in seven steps: data retrieval, pre-processing, network extraction, normalisation, mapping, analysis and visualisation. Nevertheless, many of these steps do not seem to standalone as they are done simultaneously by the software with a few clicks of the mouse. For instance, in the VOSviewer software the five steps of network extraction, normalisation, mapping, analysis and visualisation are all run almost instantly, once the required parameters are selected as desired. In fact, some authors report these procedures in just three steps: identification of data, extraction of data and analysis of data (Hallinger and Kulophas, 2019). Following is the procedure we used in this study for data collection and analysis.

\section{Data Search and Identification}

There are several bibliographic sources (online databases) which researchers can use to search and extract data for bibliometric analysis. The most significant among them are the Institute for Scientific Information (ISI) Web of Science (WoS), SCOPUS and Google Scholar (Cobo et al., 2012). In this review, we used the SCOPUS database as it is better than the WoS database in comparison to the number of publications and the coverage of journals in the field of social sciences (Hallinger, 2019). Google Scholar was not chosen as (i) retrieval of bibliometric data from the database is difficult, and (ii) the indexing procedures are not as stringent as the SCOPUS and the ISI (WOS).

On 17 August 2019, we ran an advanced search on SCOPUS database (www.scopus.com) using the fields title, abstract and keyword. We entered the following search terms "workplace learning", "job-embedded learning", "communities of practice", "learning communities", "communities of learning" and "professional learning communities". We conducted the search in just one-go as the parameters were carefully set based on preliminary search trials. Accordingly, the search results contained only journal articles, in the English Language, that were 
published in or after 1970, and under the subject area of social sciences. We also excluded those articles with the term "classroom learning" to bracket those articles reporting on classroom learning of children. Subsequently, the search generated 7,469 results which were then sorted according to the number of citations; the data was then ready to be extracted from the database. Apart from the data from the search results, we also collected information on the journal rankings of the shortlisted journals (for the top-journal analysis) from Scimago Journal Raking (www.scimagojr.com).

\section{Data Extraction and Cleaning}

Once the data is identified as described above, it was then exported from the database as a Comma-Separated Values (.csv) file. Due to restrictions imposed by the SCOPUS website, we can instantly export the full bibliometric data of the first 2,000 entries. As we only need the data of the 100 most-cited articles for our analysis, we exported only the first 2,000 and ignored the remaining.

Next, we cleaned the data by identifying incomplete or wrongly entered entries. This is done by: checking the fields (columns) to ensure that any essential field is not missed; and ensuring that the field contains data that matches with the field title (for example, the publication name should not be in the author field).

Wrong or missing entries were deleted accordingly during the data cleaning process. After cleaning the data in this manner, the first 100 entries were saved in a separate file in Microsoft Excel (.xls) format. Subsequently, the new file was then saved as a Text (tab-delimited) file so that it can be readily imported into the software for analysis.

\section{Data Analysis}

The most commonly engaged types of bibliometric networks in science mapping are keyword map, co-authorship network, citation and co-citation networks, and bibliometric coupling networks (van Eck and Waltman, 2014). In this study, we used keyword map, co-authorship among countries and bibliometric coupling networks. Furthermore, to enrich the findings, we also included analysis of publication output and citation and top journals that contributed to the production of the 100 most-cited articles on workplace learning.

There is numerous software that can be used for science mapping. These include IN-SPIRE (Wise, 1999), HistCite (Garfield et al., 2003), VantagePoint (Porter and Cunningham, 2004), Pajek (De Nooy et al., 2005), CoPalRed (Bailon-Moreno, Jurado-Alameda and Ruíz-Baños, 2006), CiteSpace II (Chen, 2006), Gephi (Bastian et al., 2009), Bibexcel (Persson et al., 2009), Network Workbench Tool (Börner et al., 2010) and VOSViewer (van Eck and Waltman, 2010). In this study, we used VOSviewer available at www.vosviewer.com for visualisation of bibliometric maps/networks. In addition to this, Microsoft Excel was used to produce graphs using the output data from VOSviewer.

There are several approaches for visualising results in science mapping. Among these, the distance-based, graph-based and timeline-based approaches are prevalent among researchers (van Eck and Waltman, 2014). In all of these approaches, there are two fundamental components displayed on the visualisation map, namely, the "nodes" represented by circles and the "edges" represent by links between the nodes. The interpretation of the maps differs in each of the three 
approaches depending on the physical appearance of nodes and edges. In the distance-based approach, the strength of the relationship between any two entities is shown by the closeness of the nodes, i.e. nodes that are close-by show a stronger relationship between the two (Fabrikant et al., 2010). On the other hand, in the graph-based approach, the distance between nodes does not indicate anything about their relatedness. Instead, such relationships are depicted by edges, i.e. when an edge is not displayed, there is no relationship between the two (van Eck and Waltman, 2014). In the final approach (timeline-based) of visualisation - also referred to as temporal analysis (Cobo et al., 2012) - the nodes are vertically positioned based on specific time periods, whereas their horizontal distance depicts the association between entities (van Eck and Waltman, 2014).

VOSviewer uses a distance-based approach for visualisation of bibliometric networks (van Eck and Waltman, 2010). However, it can also display the edges if the researcher is interested to add more visual information to the map (van Eck and Waltman, 2014). In our analysis, we decided to display the edges as well. Hence, three points should be considered when interpreting the bibliometric maps in this study:

(1) The size of the nodes indicates the occurrence (frequency) of an entity.

(2) Nodes that are close-by indicate a stronger association among the entities.

(3) The thickness of the edges (lines) between any two nodes indicates the co-occurrence of both the entities.

\section{Results and Discussion}

The Pattern of Publications and Citations

Figure 1 shows the graphical representation of the distribution of the 100 most-cited articles over the years, the total number of publications in those years, and the normalised average citation of the highly cited articles. The graphs reveal that the number of publications on the topic of workplace learning has a steady growth over the years. With just six publications in 1994, the figure has risen to 555 in 2015 . Moreover, although the number of highly cited articles seems to fall after 2010, the average citation of those articles (when normalised for the number of years after publication) is on a steady rise. Therefore, the downward slope is due to the time taken to accumulate citations for the most recent publications as compared with those published earlier. Thus, we assume that the proportion of the highly cited articles with respect to the total number of publications on the topic would be maintained in the long-run. Moreover, the graph of the average citations per article is consistently above the graph for the number of the highly cited articles indicating the persistent interest of researchers on the publications as well as on the topic. Hence, even after few decades, the topic of workplace learning is still found to be trendy and relevant."

International Contribution and Collaboration

Figure 2 shows the contribution of various countries to the publication of the hundred mostcited articles. For brevity, only those countries that have contributed to at least two publications are displayed in the figure. 
As indicated in the results, USA has contributed significantly more than the rest of the countries (33.06 per cent) to the highly cited literature on the topic of workplace learning where the number of publications from the country is twice the competitor which is the UK. Moreover, the top three countries (USA, UK and Canada) together contributed to 58.68 per cent of the publications indicating the dominance of the West.

And Europe in highly cited literature on the topic. Alternatively, the results also reveal the limited contribution to the literature on the topic from the East and Asia. Even the few countries that appeared in analysis had less than 1 per cent and 1.65 per cent of the publications, respectively. Apparently, this shows the need for studies on workplace learning from non-Western perspectives.

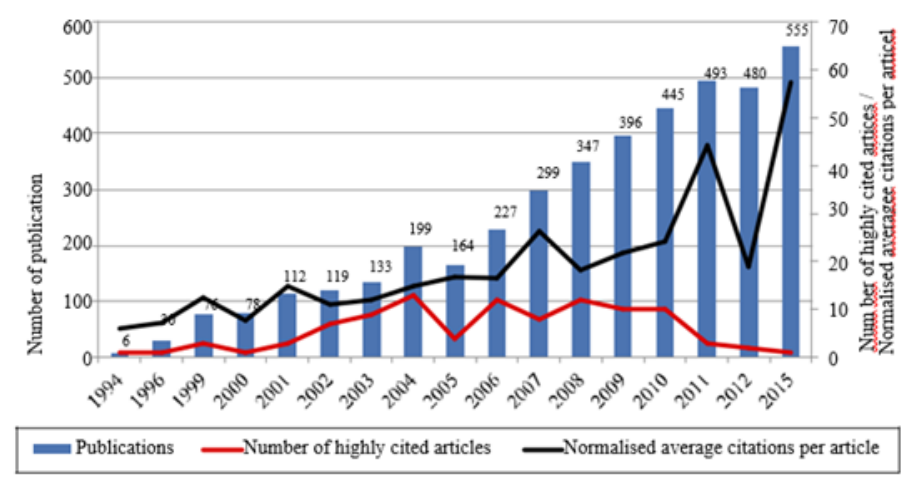

Figure 1. Total number of publications verses number of articles among the 100 most citied publications.

Note: Only those years in which at least one from the 100 most-cited articles was published are shown in the graph. Citation is normalized for the number of years after publication.

As the Sum of the contribution from all the countries is greater than 100 (which is the total number of publications analyzed in this study), it shows that some amount of collaboration has taken place among the contributing countries. Hence, VOSviewer was used to generate a collaboration network among these countries the results of which are depicted in Figure 3 . The results indicate that, with seven links, both the USA and UK have had collaborations is considered the USA becomes the top-one (link strength =10), whereas the UK gets the top-two positions (link strength $=8$ ). Each of these countries had mostly collaborated with both the USA and UK. Furthermore, although Hong Kong comes to the third place based on the number of links, Canada beats Hong Kong when the strength of the collaboration is considered as the strength of collaboration for Canada is five, whereas that for Hong Kong is four. These results depict the importance of international collaboration in producing highly cited publications on the topic. 


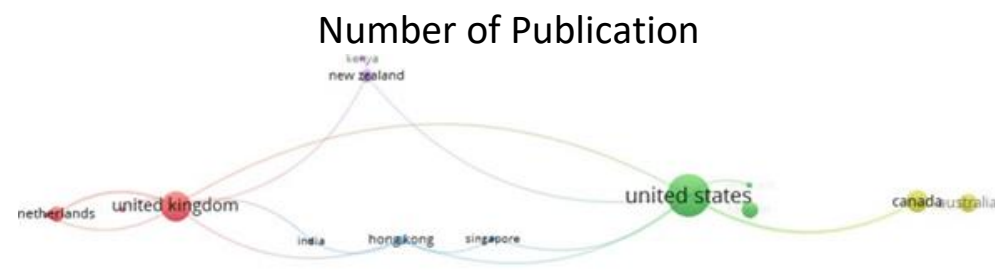

Note: A threshold of 1 was applied for the minimum number of publications by a country.

Terms that were not absolute names of countries were excluded from the analysis. Only the 14

countries out of 21 that engaged in some collaboration are displayed in the network

Fig.2 Number of publications by country based on the 100 most-cited publications

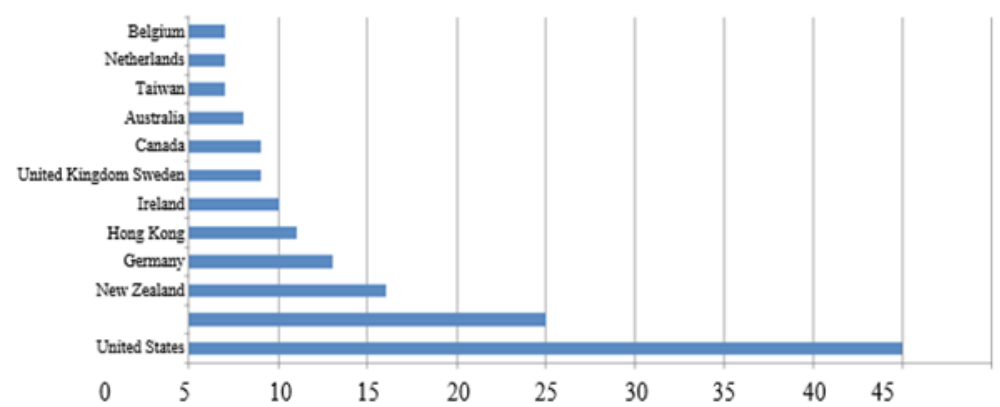

Fig.3 Collaboration network among the countries based on the number of publications

\section{Key Journals}

We extended our analysis to find out the top-journals that published the 100 most-cited articles on the topic of workplace learning. The results revealed that publications are distributed across a wide array of journals. Specifically, a total of 65 journals have published at least one of the 100 most-cited articles. However, only 12 of these journals have published two or more of those articles. For brevity, the details of these 12 journals are presented in Table I. Because the number of publications is the same across a number of journals, the journals in Table I are ranked according to the total citations of these publications from the journal.

One of the most straightforward observations from the results in Table I is that all, except one, in the top-most journals are ranked Q1 by ScimagoJR. This is an indication that highly cited publications on the topic of workplace learning generally come from top-ranked journals. Next, we observed the scores in the second last column of Table I, which shows the source normalised impact per publication (SNIP). SNIP measures the average citation per paper in a given journal as a fraction of the citation potential of that journal in the specific subject field (Waltman et al., 2013). Hence, SNIP scores greater than one indicate that the average citation per article in the journal is more than the citation potential of that journal in its subject field. Based on the results in Table I, we can conclude that all these top journals have a SNIP that is greater than one where the lowest is 1.04. This implies that all these top-journal have significant citation impact in their fields. Furthermore, this could partly explain why the Q2 ranked journal (Journal of Workplace Learning) happens to be among the top-12; it is because the journal's citation impact on the field is relatively high.

Another important observation from the results in Table I is that, as far as the journal titles are concerned, many of the top-12 journals are majors in the field of education. These include 
Vol. 10, No. 2, 2021, E-ISSN: 2226-6348 @ 2021 HRMARS

Teaching and Teacher Education, Internet and Higher Education, American Educational Research Journal, Journal of Teacher Education and Studies in Higher Education. Furthermore, few of the rest of the journals are also somehow related to education. These consist of Computers and Education, Medical Education and TESOL Quarterly. Hence, most of the scholarly efforts on workplace learning are related to education in some way.

Table I: Top-most journals among those that published the 100 most-cited publications

\begin{tabular}{|c|c|c|c|c|c|c|}
\hline \multirow[b]{2}{*}{ Journal name } & \multirow[b]{2}{*}{ TP } & \multirow[b]{2}{*}{$\mathrm{PTC}$} & \multicolumn{4}{|c|}{ iteScor SNIP } \\
\hline & & & CPP & $\mathrm{e}^{\mathrm{a}}$ & $a$ & $S J R^{b}$ \\
\hline Computers and & & 413 & & & 3.8 & 2.32 \\
\hline Education & 7 & 7 & 243 & 7.72 & 0 & Q1 \\
\hline Teaching and & & 165 & & & 2.0 & 1.51, \\
\hline Teacher Education & 6 & 8 & 276 & 3.45 & 8 & Q1 \\
\hline Journal of & & 100 & & & 1.0 & 0.42 \\
\hline Workplace Learning & 4 & 1 & 250 & 1.63 & 4 & Q2 \\
\hline & & & & & 1.7 & 0.93, \\
\hline Language in Society & 3 & 742 & 247 & 1.92 & 5 & Q1 \\
\hline Internet and Higher & & & & & 4.6 & 3.31, \\
\hline Education & 3 & 704 & 235 & 9.41 & 9 & Q1 \\
\hline Journal of Economic & & & & & 2.6 & 2.90, \\
\hline Geography & 2 & 649 & 325 & 5.04 & 6 & Q1 \\
\hline Studies in Higher & & & & & 2.2 & 1.89, \\
\hline Education & 2 & 476 & 238 & 3.28 & 7 & Q1 \\
\hline Journal of Teacher & & & & & 3.4 & 3.01, \\
\hline Education & 2 & 445 & 223 & 4.34 & 3 & Q1 \\
\hline & & & & & 1.9 & 1.97, \\
\hline Medical Education & 2 & 437 & 219 & 2.09 & 6 & Q1 \\
\hline Global & & & & & & \\
\hline Environmental & & & & 10.2 & 3.0 & 4.38, \\
\hline Change & 2 & 386 & 193 & 9 & 2 & Q1 \\
\hline American & & & & & & \\
\hline Educational & & & & & 2.7 & 3.81, \\
\hline Research Journal & 2 & 303 & 152 & 4.14 & 3 & Q1 \\
\hline & & & & & 2.2 & 2.15, \\
\hline TESOL Quarterly & 2 & 289 & 145 & 3.16 & 0 & Q1 \\
\hline
\end{tabular}

Mapping the Key Concepts on Workplace Learning

We also conducted an investigation to find out the key concepts that have been explored by researchers in the 100 most-cited articles. This was done by analysing the co-occurrence of keywords (both authors keywords and assigned keywords by the journals) using VOSviewer, the 
results of which are shown in Figure 4. As indicated in the results, the knowledge embedded in these publications can be mapped onto four major clusters. The most significant keywords in each of these clusters are "students", "learning communities", "communities of practice" and "workplace learning" in the order of cluster size.

The most repeated keyword (frequency $=12$ ) in Cluster 1 (keywords $=14$ ) is "students". It is, however, the third most repeated keyword overall. This keyword has strong associations with concepts of curriculum and knowledge acquisition (link strengths $=4$ ) both belonging to Cluster 1. Moreover, it also has strong relationships with some keywords from Clusters 2. For instance, its link strength with learning communities, e-learning and education computing are three, three and seven, respectively. The most frequent keyword in Cluster 2 (keywords $=11$ ) is "learning communities" (frequency $=18$ ). This keyword is also the second most frequent keyword overall. As indicated in the results, learning communities has got strong links with teaching, e-learning, education, education computing and interactive learning environment (link strength ranging from seven to four) all of which belong to Cluster 2. Furthermore, learning communities depicts strong associations with a number of keywords from the first cluster as well. In this regard, it portrays strong links with students, cooperative learning, learning systems, learning and teaching strategies and distance education, with link strengths ranging from seven to four.

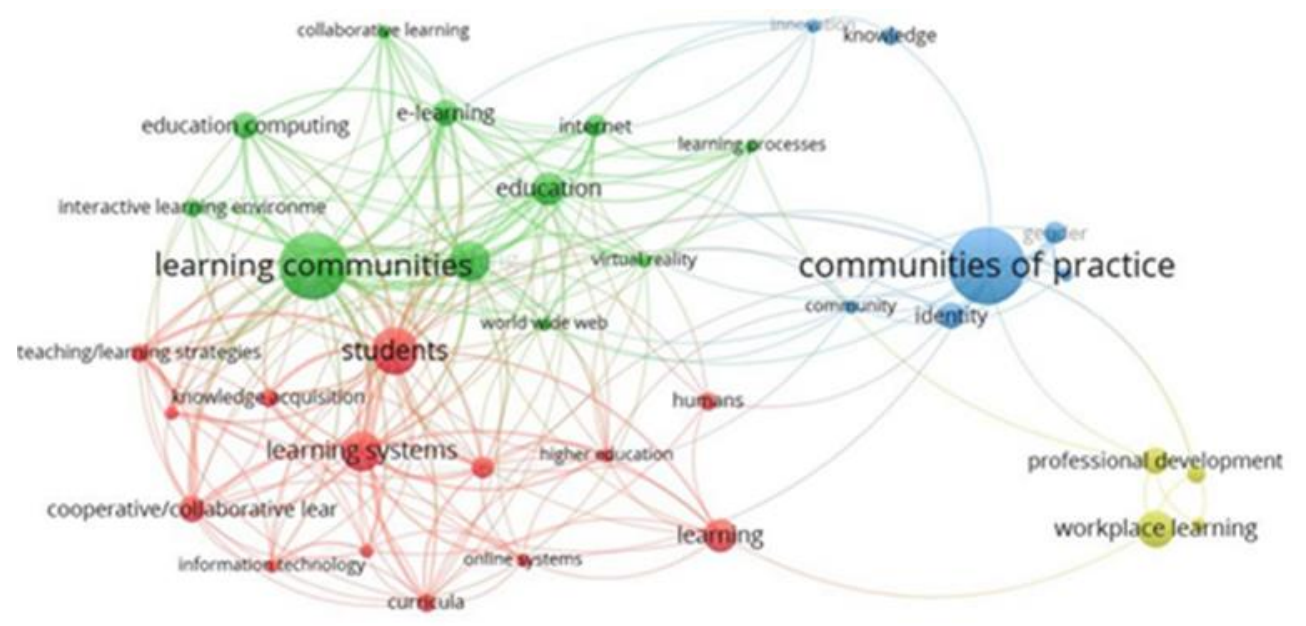

Note: A minimum occurrence of 3 was applied for the keywords whereby 37 of the 526 keywords met this threshold. A thesaurus file was used to replace duplicate words that are spelled differently. The key word "article" was excluded form the analysis

Fig. 2 Number of publications by country based on the 100 most-cited publications

\section{Publication Principles}

The As seen from Figure 4, the first and second clusters are positioned close to each other in the visualisation network - while at the same time far away from the other clusters. This shows the close association between the keywords in these clusters compared with the rest depicting a distinct school of knowledge on the topic of workplace learning. Accordingly, they are more inclined towards workplace learning that takes place in schools or educational institutions. As found in existing literature, learning communities that exist in educational institutions are 
commonly referred to as PLCs (Hord, 1997, 2008; DuFour and Eaker, 1998; DuFour, 2004). Hence, we argue that research on learning communities that exits in educational institutions is a distinct school of scholarship on workplace learning. We also claim that this group of scholarly work can be generally referred to as research on PLCs (although it does not appear on the map).

Authors Next, with regard to Cluster 3 (keywords = 7), "communities of practice" is the most significant keyword (frequency $=21$ ). In spite of belonging to the third cluster, this keyword is the most repeated keyword in the whole map. This shows researchers' attention to it in the existing literature on workplace learning. However, its relationship with other concepts is weak compared to the principle keywords in the first and second clusters. In this regard, it does not have strong associations with any keyword outside the cluster. Furthermore, the relationship within the cluster seems to be weak as two of the keywords in this cluster (knowledge and innovation) appear in a much-isolated group, far away from the rest of the keywords in the cluster. In spite of all these, the principal key work in this cluster (communities of practice) depicts close associations with two other keywords in the same cluster (gender and identity with link strengths five and four, respectively). Finally, for the last cluster, the results generally indicate the close association between workplace learning and teacher professional learning.

All of the above-reported results suggest that studies involving communities of practice were probably conducted in fields other than education. These communities of practice are more focused on perfecting the skills (or the work itself) which revolves around a shared purpose (Wenger, 1998). On the other hand, studies involving learning communities encompass a much broader - and more academic - scope of learning extending it beyond what may be acquired by simply focusing on excellence in work performance as in communities of practice (Gabelnick et al., 1990). In sum, we can argue that the knowledge base on workplace learning can be mapped onto two broad categories; one which is inclined towards educational intuitions, and the other which is associated with all other fields. It is not limited to a specific field; rather it is simply onthe-job-learning of professionals and non-professionals in virtually any field of work.

\section{Citation Network}

We also analysed the references cited in these 100 publications to find out the commonalities in the works which have been cited by authors of the 100 most-cited publications on the topic of workplace learning. This was done by carrying out a bibliometric coupling analysis using VOSviewer. The output generated by the software on this subject is displayed in Figure 5.

As shown in the results, the 100 most-cited publications can be categorised into eight clusters based on the works cited in these publications. For instance, the cluster in green (on the right) represents those which investigated computer or Web-based learning communities. Likewise, the cluster at the bottom-centre of the map (in light green) denotes those that have explored workplace learning of teachers. The distance between these two clusters (as well as between the nodes) and the relatively few links between them indicate that the cited works in these groups of publications are not so similar. 
Vol. 10, No. 2, 2021, E-ISSN: 2226-6348 @ 2021 HRMARS

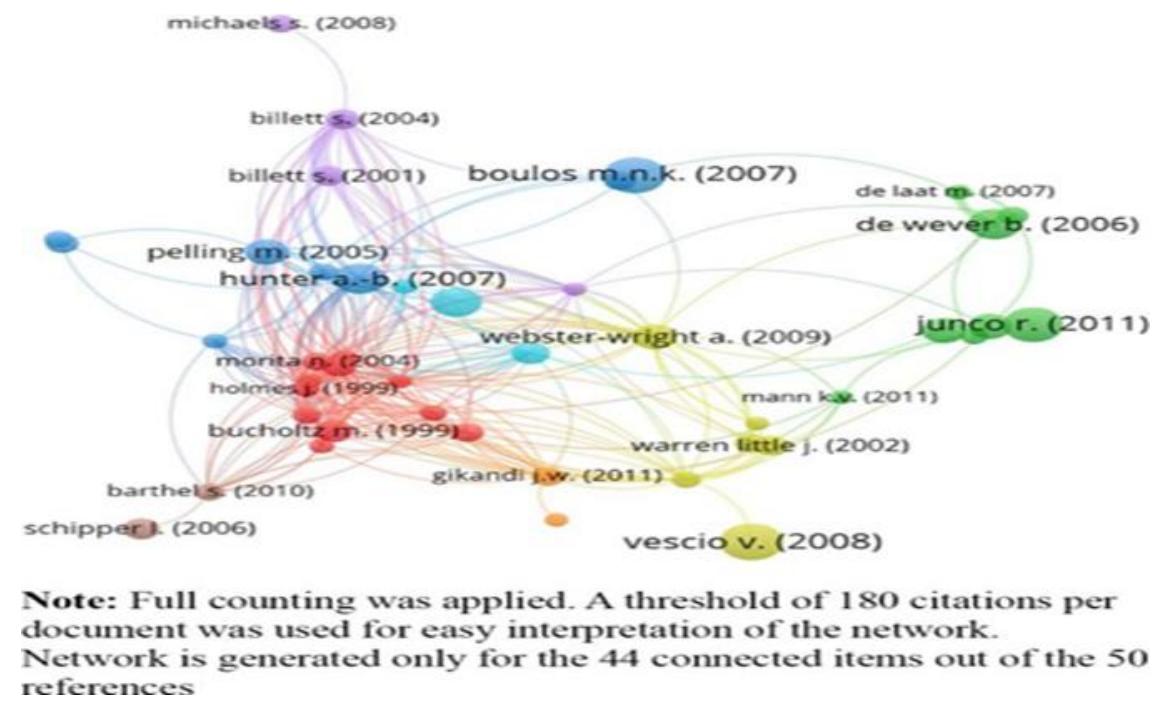

Fig. 5 Bibliometric coupling network of the articles cited in the 100 most-cited publications

Similar to the above two, the diversity of cited literature is portrayed in the two groups on the left side of the map; one at the top (in purple) and other above the centre (in dark blue). These two groups of studies are inclined towards (i) learning that is situated in very specific settings; and (ii) knowledge creation and transmission, respectively. These results portray the diversity of literature cited - as the nodes in these two clusters are quite dispersed - within and between these two groups of publications.

Unlike the above, a closer association is observed within the cluster shown on the left (below the centre in red). These publications, however, are more diverse in nature and are related to social, cultural, linguistic, psychological and demographic aspects. Moreover, the coupling strength of these publications is very high whereby it rises as to high as 34 links in certain cases. As suggested by these results, scholars who published on the topic of workplace learning cited from a large diversity of sources concurrently. The results also suggest that socio-cultural and demographic aspects were frequently and simultaneously considered by authors.

\section{Limitations}

The present bibliometric investigation is constrained by certain limitations. Firstly, our search of the literature was based on a single database. While we acknowledge the credibility of other databases such as Dimensions, PubMed and WoS, we consider that findings from SCOPUS database would be sufficient owing to its wide coverage of social sciences. We admit that the results could be somewhat different if another database or even a combination of databases is used to extract data. Furthermore, keywords were not available in 26 per cent of the articles that we used in the analysis. We regarded these as missing data. Had we replaced them with those that have provided keywords, our keyword network might look slightly different from that which is presented in this paper. Finally, our analyses were limited to data from the 100 most-cited publications only; results could have been very different had we used all the publications retrieved in the original search. Hence, the conclusions presented ahead must be interpreted keeping these restrictions in mind. 


\section{Conclusions}

In this paper, we presented a bibliometric analysis of publications on the topic of workplace learning. We analysed the citation and publication patterns of scholarly work from 1970 until the date of search (which is 17 August 2019). We further analysed the 100 most-cited articles on the topic for the contribution and collaboration of countries towards the publication as well as the key journals in which these works are published. We also represent the map of knowledge on the topic using keywords and by analysing cited references in these publications.

We found that the number of publications, as well as citations, on workplace learning is on the rise over the years since 1994. Furthermore, it was observed that most of the publications are from the USA, whereas those from Asia are very limited. We conclude that international collaboration and the number of highly cited publications are positively associated. With regard to the key journals in which these publications appear, we found that almost all are high-ranked journals. Moreover, we discovered that all these journals have a strong impact on the subject field. Hence, we suggest that researchers consider at least two journal metrics including both quartile ranking and SNIP.

With regard to mapping the knowledge, we found that there are two distinct groups. The first is those learning communities that exist in educational institutions. These not only include communities of professionals with the purpose of improving their performance but also communities of learners with common learning goals. The second is those that exist outside educational institutions. These generally include employees with shared enterprise enhancing their work performance. Similar variations were also observed in the coupling network. Hence, future researchers may benefit from the understanding that these two schools of thought exist in the knowledge base of workplace learning.

\section{Conflict of Interest}

The authors declare no conflict of interest in this research.

\section{Author Contributions}

Dr. Faeza is corresponding to this work, and contributed in writing some sections of introduction, literature review, and the conclusion. While Dr. Rouhollah has conducted the data processing and analyzing. Ms. Zahra took place in writing the whole other sections of the article. She also handled analyzing the data and writing the funding. All authors in this work had approved the final version.

\section{Acknowledgment}

All efforts paid for conducting this research return basically and individually to the authors themselves as the current study is not facilitated by any fanatical support. Thus, all authors acknowledge that it has been individually supported.

\section{References}

Bailón-Moreno, R., Jurado-Alameda, E., \& Ruiz-Baños, R. (2006). The scientific network of surfactants: Structural analysis. Journal of the American Society for Information Science and Technology, 57(7), 949-960. 
INTERNATIONAL JOURNAL OF ACADEMIC RESEARCH IN PROGRESSIVE EDUCATION AND

DEVELOPMENT

Vol. 10, No. 2, 2021, E-ISSN: $2226-6348$ @ 2021 HRMARS

Bastian, M., Heymann, S., \& Jacomy, M. (2009). Gephi: an open source software for exploring and manipulating networks. In Proceedings of the International AAAl Conference on Web and Social Media (Vol. 3, No. 1).

Bayram, B., Limon, O., Limon, G., \& Hancı, V. (2016). Bibliometric analysis of top 100 most-cited clinical studies on ultrasound in the Emergency Department. The American journal of emergency medicine, 34(7), 1210-1216.

Billett, S. (2004). Workplace participatory practices: Conceptualizing workplaces as learning environments. J Workplace Learn 16 (6): 312-324.

Börner, K., Huang, W., Linnemeier, M., Duhon, R., Phillips, P., Ma, N., ... \& Price, M. (2010). Retenetzwerk-red: analyzing and visualizing scholarly networks using the Network Workbench Tool. Scientometrics, 83(3), 863-876.

Chen, C. (2006). CiteSpace II: Detecting and visualizing emerging trends and transient patterns in scientific literature. Journal of the American Society for information Science and Technology, 57(3), 359-377.

Cobo, M. J., López-Herrera, A. G., Herrera-Viedma, E., \& Herrera, F. (2012). Science mapping software tools: Review, analysis, and cooperative study among tools. Journal of the American Society for information Science and Technology, 62(7), 1382-1402.

Wouter, D. N., Andrej, M., \& Vladimir, B. (2005). Exploratory social network analysis with Pajek, New York. Cambridge University Press, Cambridge.

Dewey, J. (1929). The sources of a science of education. Read Books Ltd, New York, NY.

DuFour, R. (2004). What is a" professional learning community"? Educational leadership, 61(8), 6-11.

DuFour, R., Eaker, R. (1998). "Professional Learning Communities at Work: Best Practices for Enhancing Student Achievement", National Education Service, Bloomington, IN.

Fabrikant, S. I., Montello, D. R., \& Mark, D. M. (2010). The natural landscape metaphor in information visualization: The role of commonsense geomorphology. Journal of the American Society for Information Science and Technology, 61(2), 253-270.

Fellnhofer, K. (2019). Toward a taxonomy of entrepreneurship education research literature: A bibliometric mapping and visualization. Educational Research Review, 27, 28-55.

Gabelnick, F., MacGregor, J., Matthews, R. S., \& Smith, B. L. (1990). Learning Communities: Crating Connections Among Students, Faculty, and Disciplines, Jossey-Bass (J-B TL Single Issue Teaching and Learning Series), San Francisco, CA.

Hallinger, P. (2019). Science mapping the knowledge base on educational leadership and management from the emerging regions of Asia, Africa and Latin America, 1965-2018. Educational Management Administration \& Leadership, 48(2), 209-230.

Hallinger, P., \& Kovačević, J. (2019). A bibliometric review of research on educational administration: Science mapping the literature, 1960 to 2018. Review of Educational Research, 89(3), 335-369.

Hallinger, P., \& Kulophas, D. (2019). The evolving knowledge base on leadership and teacher professional learning: a bibliometric analysis of the literature, 1960-2018. Professional development in education, 46(4), 521-540. 
INTERNATIONAL JOURNAL OF ACADEMIC RESEARCH IN PROGRESSIVE EDUCATION AND

DEVELOPMENT

Vol. 10, No. 2, 2021, E-ISSN: 2226-6348 @ 2021 HRMARS

Hernández, J. B., Chalela, S., Arias, J. V., \& Arias, A. V. (2017). Research trends in the study of ICT based learning communities: A bibliometric analysis. EURASIA Journal of Mathematics, Science and Technology Education, 13(5), 1539-1562.

Hord, S. M. (1997). Professional learning communities: Communities of continuous inquiry and improvement., Southwest Educational Development Laboratory, TX.

Hord, S. M. (2008). Evolution of the professional learning community. The Learning Professional, 29(3), 10-13.

Kolkailah, A. A., Fugar, S., Vondee, N., Hirji, S. A., Okoh, A. K., Ayoub, A., ... \& Golzar, Y. (2018). Bibliometric analysis of the top 100 most cited articles in the first 50 years of heart transplantation. The American journal of cardiology, 123(1), 175-186.

Liu, B., Liu, S., Alastra, A. J., Mahato, D., Tayag, E. C., Cortez, V. A., \& Siddiqi, J. (2019). The 100 most cited vs. most relevant articles in the journal of neurosurgery: a bibliometric analysis. Cureus, 11(4).

Morris, S. A., \& Van der Veer Martens, B. (2008). Mapping research specialties. Annual review of information science and technology, 42(1), 213-295.

Murphy, J., \& Adams, J. E. (1998). Reforming America's schools 1980-2000. Journal of Educational Administration, 36(5), 426-441.

Alan, L. P., Scott. Cunningham. (2004). Tech Mining: Exploiting New Technologies for Competitive Advantage, JohnWiley \& Sons, Hoboken, NJ.

Small, H. (1997). Update on science mapping: Creating large document spaces. Scientometrics, 38(2), 275-293.

Stoll, L., Bolam, R., McMahon, A., Wallace, M., \& Thomas, S. (2006). Professional learning communities: A review of the literature. Journal of educational change, 7(4), 221-258.

Van Eck, N. J., \& Waltman, L. (2010). Software survey: VOSviewer, a computer program for bibliometric mapping. scientometrics, 84(2), 523-538.

Van Eck, N. J., \& Waltman, L. (2014). Visualizing bibliometric networks. Y.in Ding, R. Rousseau, and D. Wolfram, (Eds) Measuring Scholarly Impact, Springer, Cham, 285-320.

Waltman, L., Van Eck, N. J., Van Leeuwen, T. N., \& Visser, M. S. (2013). Some modifications to the SNIP journal impact indicator. Journal of informetrics, 7(2), 272-285.

Wenger, E. (1998). Communities of practice: Learning as a social system. Systems thinker, 9(5), 23.

Wenger, E. C., \& Snyder, W. M. (2000). Communities of practice: The organizational frontier. Harvard business review, 78(1), 139-146.

Wise, J. A. (1999). The ecological approach to text visualization. Journal of the American society for information science, 50(13), 1224-1233.

Zhang, X., Estoque, R. C., Xie, H., Murayama, Y., \& Ranagalage, M. (2019). Bibliometric analysis of highly cited articles on ecosystem services. PloS one, 14(2), e0210707.

Zupic, I., \& Cater, T. (2015). Bibliometric methods in management and organization. Organizational Research Methods, 18(3), 429-472. 